\title{
Post-Call Rounds
}

\author{
Mohammed Samee, MD, RN
}

Advocate Illinois Masonic Medical Center, Department of Internal Medicine, Chicago, IL, USA.

\section{$\boldsymbol{P}_{\text {Ost-Call rounds }}$}

A nervous wreck, palms sweaty, head and eyelids heavy, not ready for the showdown.

Thoughts turned flip-side, right-side, upside down.

Chief complaint?

The fact that I stand here turning

beet as a red, hat as a madder, hot as a...

Wait.

Don't flatter yourself

because your coat is grayer or bluer than mine.

Fine lines on your face show a time

when yours was mine

and lips stuttered with every word uttered:

"I can't hear you, Doctor - don't mutter!"

Heart fluttered as I sputtered

my way thru these morning theatrics.

Slick tricks to keep the sick straight,

in my head. Thoughts of bed,

lead legs make others beg

my show was over.

Scrub odors join eye floaters

for those not seasoned to the battle,

to saddling war-horses too old to straddle.

Step back!

It's my time to shine,

laced and strapped to the waist, in evidence based.

Ask me now, Dr. Great.

It's not UpToDate, it's up to fate

when you're inches from Heaven's gate.

Published online May 30, 2014

Corresponding Author: Mohammed Samee, MD, RN, Advocate Illinois Masonic Medical Center, Department of Internal Medicine, 836 West Wellington Avenue, Suite 7304, Chicago, IL 60657, USA (email: Mohammed.samee2@advocatehealth.com).

J Gen Intern Med 29(10):1424

DOI: $10.1007 / \mathrm{s} 11606-014-2872-3$

(c) Society of General Internal Medicine 2014 